\title{
Relationship between age, random blood sugar, BMI and WHCR and how it is affected by, gender and medicine
}

\section{Introduction}

Medical literature claims level of random blood glucose (RBG) rises with age. There are references which state body mass index (BMI) and waist hip circumference ratio (WHCR) also affect blood sugar. However, there is no description of the pattern. Treatment of hyperglycaemia, either with oral medicine or insulin affects RBG, BMI, and WHCR. Here also no quantitative relationship is available. We carried out an explanatory study in 2016 on local population to determine the quantitative relationship amongst them. The relationships are presented here in mathematical and graphical forms.

\section{Approach}

There are two categorical variables in the study - (A). Fixed ${ }^{1}$ gender - male or female, ${ }^{2}$ glycaemia - unknown, on oral medicine or on insulin. There are four (B) continuous variables ${ }^{3}$ Age (in complete years), ${ }^{4}$ RBG (Random Blood Glucose), ${ }^{5}$ BMI (Body Mass Index $=\left\{\right.$ weight in kilogram/ height in meter $\left.{ }^{2}\right\}$ ), ${ }^{6}$ WHCR (Waist Hip Circumference Ratio). Duration of diabetes, Period of treatment, Life style and Type of food are likely to be major factors. But we dropped these from study, fearing patients' response are likely to be errorprone. Out of curiosity, we also wanted to find out whether there is any association between glycaemia and family history.

\section{Data collection}

The study is on patients, not general population, simply because of shortage of fund. We collected data on patients, with their consent, at first at a GP (general physician) clinic. Since we did not get enough data on glycaemia patients on insulin at this clinic, we subsequently conducted a similar study on glycaemia patients in a different clinic.

Data were collected through a combination of questionnaire and a few measurements (height, weight, waist circumference, hip circumference, random capillary blood glucose) applied to those who agreed to be tested. We excluded patients with age less than or equal to 10 years.

202 patients were observed, 23 patients were too weak, 10 patients did not wish to be measured, 3 patients were underage, 7 patients' records were anomalous, resulting in a final of 182 observations.

The final data set consists of - (a) Date, (b) Centre, (c) Sl.no, ${ }^{4}$ Age in completed years $\},{ }^{5}$ Gender [male/female], ${ }^{6}$ History \{family history of glycaemia- unknown, no glycaemia, glycaemia. Family includes parents and siblings only.\}, ${ }^{7}$ Glycaemia (no medicine, oral medicine, insulin $\},{ }^{8}$ Height $\{$ in meter(m), measured using stadiometer $\},{ }^{9}$ Weight $\{$ in kilogram $(\mathrm{Kg})$, measured with weighing machine for medical study $\},{ }^{10}$ Waist \{circumference in centimetres, measured with measuring tape\}, (11) Hip \{circumference in centimetres,measured with measuring tape $\}$, (12) RBG (mg/dl as measured with glucometer\}, (13) BMI \{computed\} and (14) WHCR \{computed\}.
Volume 6 Issue 2 - 2018

\author{
Paritosh Roy,' AtreyeeGhosh,' Debasish \\ Roy ${ }^{2}$ \\ 'Meha Diabetes Foundation, India \\ ${ }^{2}$ Computer and Statistical Service Centre, Indian Statistical \\ Institute, India
}

Correspondence: Paritosh Roy, Meha Diabetes Foundation, Kolkata, India, Email paritroy@gmail.com

Received: September 02, 2017 | Published: March 28, 2018

\section{Results and interpretation}

Table I(A) History* glycaemia cross-tabulation

\begin{tabular}{lllll}
\hline History & Glycaemia & & & Total \\
\hline & Unknown & Oral & Insulin & \\
Yes & 29 & 34 & 14 & 77 \\
No & 58 & 33 & 8 & 99 \\
Unknown & 0 & 5 & 1 & 6 \\
Total & 87 & 72 & 23 & 182 \\
\hline
\end{tabular}

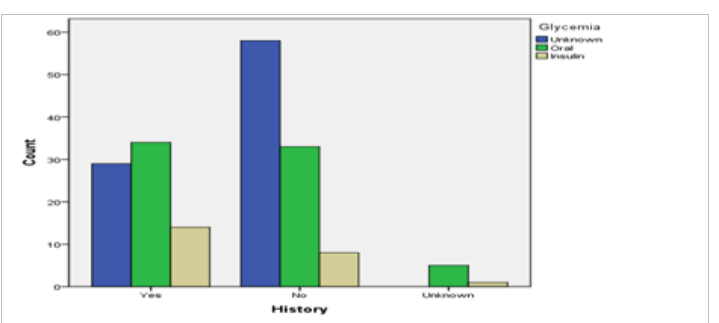

Chart I Stacked Bar Chart.

Table I(B) Chi-square tests

\begin{tabular}{llll}
\hline & Value & df & $\begin{array}{l}\text { Asymp. Sig. } \\
\text { (2-sided) }\end{array}$ \\
\hline Pearson Chi-Square & 14.797 & 4 & 0.005 \\
Likelihood Ratio & 16.972 & 4 & 0.002 \\
\hline
\end{tabular}

Table 1(A) \& Chart 1 shows the association between family history and glycaemia of the sampled unit in tabular and chart form. Table 1(A), being a cross-tabulation, shows something more. The number of individuals on insulin is low. Most of them (14 out of 23) have record of family history of glycaemia. This may be because they went to check on family history after they were detected with glycaemia. For those on oral medicine, the family history of finding glycaemia or not is almost equal (34 and 33). 
The number of people on oral medicine is quite high, almost equal to that of people not using oral medicine. This implies glycaemia is very prevalent, even in the small population we observed.

One peculiar finding is that none of the patients who are not being treated for glycaemia say that he/she is not aware of family history, and twice the population respond in negative!

Table 1(B) is for statisticians. What it means, in common-man's language (We include common-woman too, for feminists), is that the association is not due to chance. Since time goes forward only (except in science fiction, until now), we are forced to conclude that heredity is a major factor for glycaemia. We expect the genes are responsible.

Table 2(A) Descriptive statistics

\begin{tabular}{lllll}
\hline & Minimum & Maximum & Mean & $\begin{array}{l}\text { Std. } \\
\text { Deviation }\end{array}$ \\
Age & $1 \mathrm{I}$ & 86 & 48.27 & 15.484 \\
RBG & $7 \mathrm{I}$ & 522 & 152.76 & 88.911 \\
BMI & $14.49 \mathrm{I}$ & 46.521 & 25.81184 & 4.710808 \\
WHCR & 0.78 & 1.09 & 0.93378 & 0.066006 \\
\hline
\end{tabular}

Table 2(A) above is for statisticians. In common man's language what are implied as:-

i. The observed age is between 11 and 86. Since our goal was to drop boys and girls at or below age of 10, screening has been done properly. The person aged 86 was quite fit.

ii. RBG is in the range of 71 to $522 \mathrm{gm} / \mathrm{dl}$. None are seriously ill.

iii. BMI is between 14.5 and $46.5 \mathrm{~kg} / \mathrm{m}^{2}$. The range is between underweight to grade III obese. The result is startling! We wish to conduct further study on this feature.

iv. WHCR is between 0.78 and 1.09. Many observations are substantially increased as per World Health Organization [WHO] standard. Probably an Indian Standard may be set up. We wish to conduct further studies in future.

Table 3(A) Pearsonian linear correlation coefficients

\begin{tabular}{|c|c|c|c|c|c|}
\hline & & Age & RBG & BMI & WHCR \\
\hline \multirow[t]{2}{*}{ Age } & $\begin{array}{l}\text { Pearson } \\
\text { Correlation }\end{array}$ & I & $.359 * *$ & $.153^{*}$ & $.447 * *$ \\
\hline & Significance & & 0 & 0.039 & 0 \\
\hline \multirow[t]{2}{*}{ RBG } & $\begin{array}{l}\text { Pearson } \\
\text { Correlation }\end{array}$ & $.359 * *$ & I & -0.001 & $.222^{* *}$ \\
\hline & $\begin{array}{l}\text { Significance } \\
\text { (2-tailed) }\end{array}$ & 0 & & 0.993 & 0.003 \\
\hline \multirow[t]{2}{*}{ BMI } & $\begin{array}{l}\text { Pearson } \\
\text { Correlation }\end{array}$ & $.153^{*}$ & -0.001 & I & $.28 I^{* *}$ \\
\hline & $\begin{array}{l}\text { Significance } \\
\text { (2-tailed) }\end{array}$ & 0.039 & 0.993 & & 0 \\
\hline \multirow[t]{3}{*}{ WHCR } & Pearson & $.447 * *$ & $.222 * *$ & $.281 * *$ & 1 \\
\hline & Correlation & & & & \\
\hline & $\begin{array}{l}\text { Significance } \\
\text { (2-tailed) }\end{array}$ & 0 & 0.003 & 0 & \\
\hline
\end{tabular}

Table 3(A) shows:

a. Age is highly significantly correlated with RBG, BMI and WHCR. Since Age cannot be the effect, we are forced to accept the theory that age linearly affects RBG, BMI and WHCR. Since the correlations are all positive, we conclude RBG, BMI and WHCR all increase with age.

b. BMI is negatively related with RBG. This, in common man's language implies that if BMI is more, RBG will be less and viceversa. But the result is not at all conclusive. This may be due to chance. Further studies are required before drawing conclusion.

c. WHCR is positively significantly related with RBG. This is not due to chance. May be body fat is the underlying reason for both of these.

Table 3(B) Best linear estimators

\begin{tabular}{llllllll}
\hline & Constant & $\begin{array}{l}\text { Standard } \\
\text { Error }\end{array}$ & Age & $\begin{array}{l}\text { Standard } \\
\text { Error }\end{array}$ & $\begin{array}{l}\text { Multiple } \\
\text { Linear } \\
\text { Correlation }\end{array}$ & $\begin{array}{l}\text { Variance } \\
\text { Ratio }\end{array}$ & $\begin{array}{l}\text { Significance } \\
13.266\end{array}$ \\
\hline RBG & 53.198 & 20.245 & 2.063 & 0.399 & 0.359 & 0 & 0 \\
BMI & 23.565 & 1.136 & 0.047 & 0.022 & 0.153 & 4.312 & 0 \\
WHCR & 0.842 & 0.014 & 0.002 & 0 & 0.447 & 45.056 & 0 \\
\hline
\end{tabular}

Table 3(B) provides equations for best linear estimations of RBG, BMI and WHCR given age. In layman terms, RBG can be estimated as $53.198+2.063 *$ Age and so on. Standard Error of estimated parameters indicates that the estimates are quite stable. Note that even though the variance ratio is highly significant, multiple correlation coefficients is not. This corroborates layman's theory that there are other factors besides age.

Table 3(C) Pearsonian partial correlations after removal effect of age

\begin{tabular}{|c|c|c|c|c|}
\hline $\begin{array}{l}\text { Control } \\
\text { Variables }\end{array}$ & & RBG & BMI & WHCR \\
\hline \multirow[t]{6}{*}{ Age } & Correlation & I & -0.06 & 0.074 \\
\hline & Significance (2-tailed) & & 0.42 & 0.324 \\
\hline & BMI Correlation & -0.06 & I & $0.24 I$ \\
\hline & Significance (2-tailed) & 0.42 & & 0.001 \\
\hline & WHCR Correlation & 0.074 & 0.241 & I \\
\hline & Significance (2-tailed) & 0.324 & 0.001 & \\
\hline
\end{tabular}

Since Age affects all others, Table 3(C) is constructed after removing effect of it on others. This table shows:

i. RBG and BMI are negatively related. But the result is not conclusive. The observation may be due to chance.

ii. RBG and WHCR are positively related. But the result is not conclusive. The observation may be due to chance.

iii. WHCR and BMI are significantly positively related. This cannot be due to chance.

The linear relationship is of the form: - WHCR (given Age) $=$ 0.003* BMI (given Age) or BMI (given Age) $=26+19 *$ WHCR (given Age).

Now we bring in gender and Glycaemia into the picture. We have constructed tables for minimum, maximum, mean and standard devitation of the four vatiables like Table 2(A), corresponding to 
the six groups. Since no new conclusion could be drawn from these tables, we dropped these.

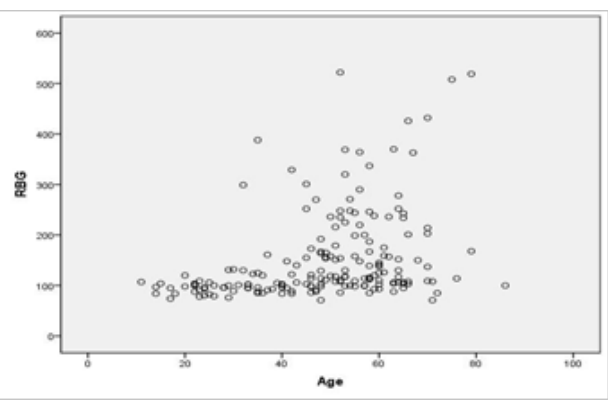

Chart 2 Scatterplot of RBG vs Age when Gender and Glycaemia are not considered.

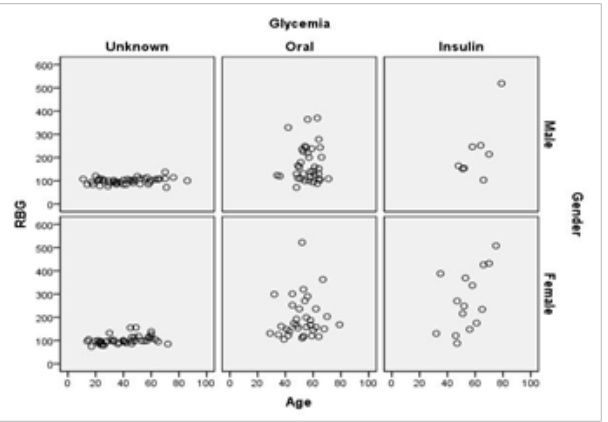

Chart 3 Scatterplot of RBG vs Age when Gender and Glycaemia are considered.
Charts $2 \& 3$ show the effect of Gender and Glycaemia on the relationship between blood sugar and age.

Note:-

1. Even though we have shown in Table 3(A) that the relationship between blood sugar and age to be linear, the situation is more complicated. The minimum blood sugar seems to remain constant over age. Maximum, mean and standard deviation of blood sugar (variation for layman) increases over age.

2. The picture is very similar with males and females whose Glycaemia is unknown and who are not on medicine for glycaemia. Minimum blood pressure remains almost the same over age, maximum, mean and standard deviation increases over age.

3. The picture changes completely for both males and females when they are detected with mild level of glycaemia and are put on oral medicine. We cannot say blood sugar increases with age. The picture is like a blob, where any and all curves are equally good or equally bad.

4. The pattern of increasing blood sugar with age seems to return for males and females when they are detected with severe level of glycaemia and are put on insulin injection. But since we have not got sufficient number of observations here, we cannotclaim this with any certainty.

5. Since the pattern differs in different groups, the usual statistical techniques of t-test and F-test are not applicable to test whether there are significant differences between the six groups. That the patterns are not similar can be identified from Table 4(C) below.

Table 4(C) Group-wise linear regression of RBG on age

\begin{tabular}{|c|c|c|c|c|c|c|c|}
\hline Group & Constant & Standard Error & Age & $\begin{array}{l}\text { Standard } \\
\text { Error }\end{array}$ & $\begin{array}{l}\text { Multiple } \\
\text { Linear } \\
\text { Coefficient }\end{array}$ & $\begin{array}{l}\text { Variance } \\
\text { Ratio }\end{array}$ & Significance \\
\hline Male, None & 91.622 & 4.817 & 0.171 & 0.104 & 0.247 & 2.732 & 0.106 \\
\hline Male, Oral & 153.478 & 91.146 & 0.325 & 1.612 & 0.034 & 0.041 & 0.842 \\
\hline Male, Insulin & -292.361 & 217.647 & 8.487 & 3.521 & 0.701 & 5.81 & 0.053 \\
\hline Female, None & 84.994 & 7.132 & 0.423 & 0.167 & 0.368 & 6.439 & 0.015 \\
\hline Female, Oral & 161.154 & 73.354 & 0.651 & 1.381 & 0.082 & 0.222 & $0.64 I$ \\
\hline Female, Insulin & -40.226 & 140.453 & 5.766 & 2.53 & 0.534 & 5.193 & 0.04 \\
\hline
\end{tabular}

It is apparent that for Male or Female on Oral medicine, estimation using linear regression is insignificant. For Male and Female on Insulin injection, the estimated RBG may even be negative!

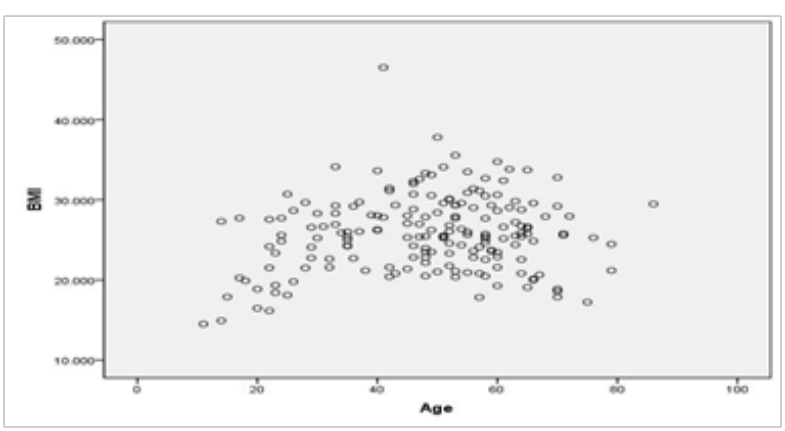

Chart 4 Scatterplot of BMI vs Age when Gender and Glycaemia are not considered.

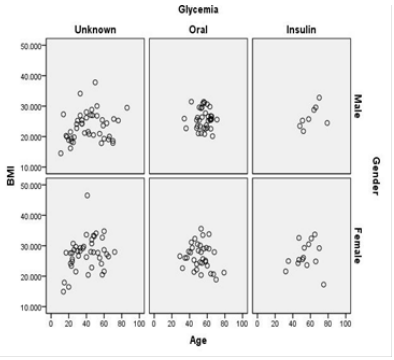

Chart 5 Scatterplot of BMI vs Age when Gender and Glycaemia are considered.

Note that the situation of BMI vs Age as shown in Chart $4 \&$ Chart 5 similar to that of RBG vs Age as shown on Chart 2 \& Chart 3, except minimum BMI is not fixed over Age and variation in BMI is more than RBG. Table 5(c) for estimating BMI given Age is given below. The table is similar to Table 4(C). 
Table 5(C) Group-wise linear regression of BMI on age

\begin{tabular}{|c|c|c|c|c|c|c|c|}
\hline Group & Constant & Standard Error & Age & $\begin{array}{l}\text { Standard } \\
\text { Error }\end{array}$ & $\begin{array}{l}\text { Multiple } \\
\text { Linear } \\
\text { Coefficient }\end{array}$ & $\begin{array}{l}\text { Variance } \\
\text { Ratio }\end{array}$ & Significance \\
\hline Male, None & 21.015 & I.79| & 0.053 & 0.038 & 0.208 & 1.907 & 0.175 \\
\hline Male, Oral & 26.151 & 3.824 & -0.007 & 0.068 & 0.016 & 0.009 & 0.923 \\
\hline Male, Insulin & 15.875 & 7.356 & 0.174 & 0.119 & 0.512 & 2.134 & 0.194 \\
\hline Female, None & 23.273 & 2.26 & 0.104 & 0.053 & 0.293 & 3.845 & 0.057 \\
\hline Female, Oral & 30.282 & 3.409 & -0.073 & 0.064 & 0.193 & 1.283 & 0.266 \\
\hline Female, Insulin & 24.617 & 5.708 & 0.039 & 0.103 & 0.105 & 0.146 & 0.709 \\
\hline
\end{tabular}

One interesting finding is that BMI decreases with Age for both Male and Female on Oral medicine for glycaemia, but not so when Insulin injection is applied. However, we are not in a position to make this claim with any certainty. The finding is statistically anomalous.

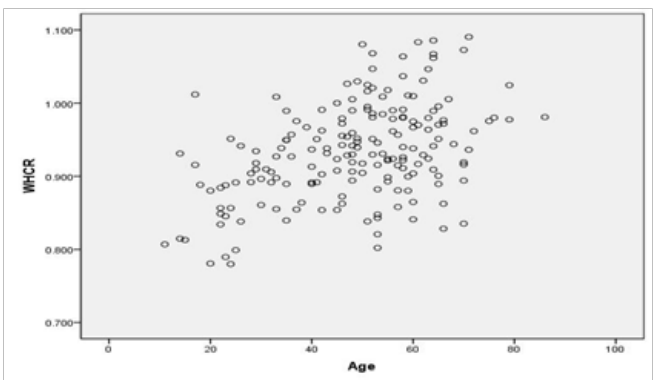

Chart 6 Scatterplot of WHCR vs Age When Gender and Glycaemia are not considered.

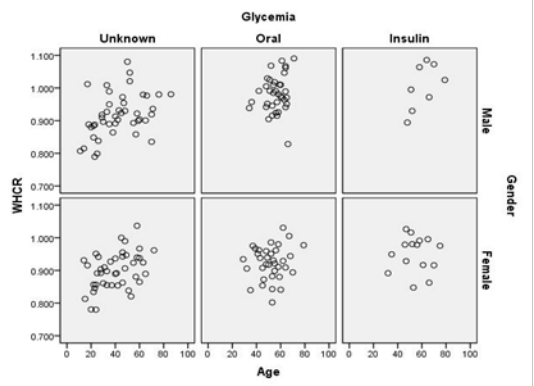

Chart 7 Scatterplot of WHCR vs Age when Gender and Glycaemia are considered.

Note that the situation of WHRC vs Age is similar to BMI vs Age. Hence we do not produce any more tables and charts.

\section{Conclusion}

i. Heredity is an important factor for glycaemia. Our study gives us no scope to doubt it.

ii. Age affects RBG, BMI and WHCR. The relationship can be assumed to be linear. We have derived these equations in this paper.

iii. When linear effect of Age is eliminated from RBG, BMI and WHCR, the last two are still highly inter-related. The equations are derived in this parer. Residual RBG is unaffected by residual BMI and/or residual WHCR. A cohort study is required to confirm this. iv. Minimum RBG does not change over age, maximum, average and variation do. This result is true when - (1) when whole population, (2) when male population without medicine or (3) female population without medicine - is considered.

v. There are indications that BMI decreases with Age for both Male and Female hyperglycaemic patients on oral mdication, but not so when insulin injection is applied. However, the results are statistically insignificant and inconclusive. Further studies are required.

vi. BMI and WHRC are always related, irrespective of Age.

\section{Acknowledgement}

We acknowledge Ms Sarani Chakraborty for her contribution in data collection.

\section{Conflict of interest}

None.

\section{References}

1. Waist Circumference, Waist Hip Ratio: Report of a WHO Expert Consultation. Geneva. 2008;8-11.

2. Afshin A, Forouzanfar MH, Reitsma MB, et al. Health effects of overweight and obesity in 195 Countries over 25 Years. The GBD 2015 obesity Collaborators. N Engl J Med. 2017;377(1):13-27.

3. Body weight is positively related to insulin resistance. But no difference in relation between degree of insulin resistance and index of adiposity. Am J Clin Nutr. 2006;83(1):47-51.

4. Farin HM, Abbasi F, Reaven GM, et al. Body mass index and waist circumference both contribute to differences in insulin mediated glucose disposal in non diabetic adults. Am J Clin Nutr. 2006;83(1):47-51.

5. Waist circumference is a simple and precise anthropometric marker for Type 2 Diabetes risk. Sex is also an influencing factor. Ann Univ Mariae Curie Sklodowska Med. 2003;58(1):413-419.

6. Łopatyński J, Mardarowicz G, Szcześniak G. A comparative evaluation of waist circumference waist to hip ratio. waist to height ratio and body mass index as indicators of impaired glucose tolerance and as risk factors for type 2 diabetes mellitus. Ann Univ Mariae Curie Sklodowska Med. 2003;58(1):413-419.

7. Chan JM, Rimm EB, Colditz GA, et al. Obesity, Fat Distribution, Weight Gain as Risk Factors for Clinical Diabetes in Men. Diabetes Care. 1994;17(9):961-969. 
8. Associations between Body Composition Indices and Metabolic Disorders in Chinese Adults: A Cross-Sectional Observational Study. Chin Med J (Engl). 2018;131(4):379-388.

9. Jabłonowska-Lietz B, Wrzosek M, Włodarczyk M, et al. New indexes of body fat distribution, visceral adiposity index, body adiposity index, waist-to-height ratio, and metabolic disturbances in the obese. Kardiol Pol. 2017;75(11):1185-1191.
10. Vikram NK, Latifi AN, Misra A, et al. Waist-to-Height Ratio Compared to Standard Obesity Measures as Predictor of Cardiometabolic Risk Factors in Asian Indians in North India. Metab Syndr Relat Disord. 2016;14(10):492-499. 